\title{
離散時間・擬線形系の部分実現および実時間部分実現理論 ${ }^{\dagger}$
}

\author{
長谷川 泰 道*・松尾、強** \\ Partial Realization and Real-Time, Partial Realization Theory \\ of Discrete-Time Pseudo-Linear Systems \\ Yasumichi HaSEgawA* and Tsuyoshi Matsuo**
}

The realization problem of pseudo-linear systems had been presented with the following realization theorem.

Realization theorem 「For any invariant input-response map (equivalently, any input/output map with causality and time-invariance), there exist at least two canonical pseudo-linear systems which realize it. Moreover any two canonical pseudo-linear systems with same behavior are isomorphic each other.」 Where electric circuits with FET transistors are examples of pseudo-linear systems. Moreover, the finite-dimensionality of pseudo-linear systems had been discussed.

In this paper, being based on the ubove results, we will discuss problems of the partial and real-time partial realization. The problems can be roughly described as the follows. The partial realization problem $\lceil$ For a given partial time-invariant input response map by multi-experiments, find uniquely a minimal dimensional pseudo-linear system which partially realizes it. The real-time partial realization problem $\lceil$ For a given partial time-invariant input response map by single-experiment, find uniquely a minimal dimensioal pseudo-linear system which partially realizes it. And the following results are obtained.

(1) A necessary and sufficient condition for minimal partial realization systems to be unique is given by the rank condition of input/output matrix.

(2) For a given partial time-invariant input response map by multi-experiments, an algorithm to obtain the minimal partial realization system is given.

(3) For a given partial time-invariant input response map by single-experiment, an algorithm to obtain the minimal realization system is given.

We conclude that these results about partial realization are the extention of the finite-dimensional, constant, linear systems to a non-linear system.

Key Words : pseudo-linear system, partial realization theory, real-time partial realization theory, nonlinear system, discrete-time system

\section{1.はじめに}

本論文では 離散時間系を取り扱う。筆者らは文献 1) において擬線形系の実現問題を定義し, 擬線形系が時不 変入力応答関数 (因果律および時不変を満たす任意の入 出力写像)により特徵づけられるつぎの実現定理を得た. 実現定理：「任意の時不変入力応答関数に対しそれを実

†第 35 回自動制御連合講演会で発表 $(1992 ・ 10)$

* 岐皁大学工学部 岐阜市柳戸 1-1

** 東邦大学理学部 船橋市三山 2-2-1

* Faculty of Engineering, Gifu University, Gifu

** Faculty of Science, Toho University, Funabashi (Received April 1, 1994)
現する正準(擬可到達であり，可観測である)擬線形系が 必ず存在し，任意の二つの正準実現系は互いに同形であ る」

また，擬線形系の具体例として.FETを含む電気回路 があることを示した。ささらに，文献 2)において有限次元 擬線形系を論じ，その主な成果として，有限次元擬線形 系が正準であるための必要十分条件を導出し, 有限次元 正準擬線形系の同形類の代表元として擬可到達標準系が 存在することを示し, 時不変入力応答関数が有限次元擬 線形系の挙動であるための必要十分条件を与えた。さら にその条件を満たす与兄られた時不変入力応答関数か ら，それを実現する擬可到達標準系を求める手順を与兄 
た.

本論文では，それらの成果に基づいて擬線形系の部分 実現および実時間部分実現問題を論じる。部分実現, 実 時間部分実現問題は大ざっぱにいえば，それぞれつぎの ようになる。

部分実現問題：「任意に与兄られた部分時不変入力応答 関数 (多重実験による有限個の入出力デー夕) と同じ挙動 (入出力関係)をもつ最小次元の擬線形系を求めよ」

実時間部分実現問題：「任意に与えられた時不変入力応 答関数の単一実験による入出力デー夕から 対象と同じ 挙動をもつ最小次元の擬線形系を求めよ」

本論文の成果は Kalman らが確立した有限次元定係 数線形系の部分実現理論 ${ }^{3)}$ の擬線形系への拡張になって いる.

\section{2. 準備}

本章では部分実現問題を論じるのに必要な内容を文献 1），2）から抽出する。なお，つぎのような記号を用いる.

$N$ は非負の整数の集合(時間の集合を表わす)，Kはあ る体 (field) であり, $\boldsymbol{K}^{n}$ は体 $\boldsymbol{K}$ 上の $n$ 次元ベクトル空 間, $\boldsymbol{K}^{n \times n}$ は $n \times n$ 行列の集合である. $F(A, B)$ は集合 $A$ から集合 $B$ への関数の全体, $L(A, B)$ は線形空間 $A$ 名 ら線形空間 $B$ への線形写像の全体， $L(A)=L(A, A)$ を それぞれ表わす、《X》は集合 $X$ を含む最小の線形空間を 表わす。

\section{1 入出力関係}

本節では本論文で取り扱う入出力写像を考察する，U を入力值集合(入力が取りうる值の集合)とし，Uをアル ファベットとするワード(語)の集合 $U^{*}$ を入系列の集 合とする. 入力 $\omega=\omega(n) \omega(n-1) \cdots \omega(1) \in U^{*}$ の長さ $|\omega|$ を $n$ と定義する. ただし $n \in N$ である. そこで連鎖の演 算 $\mid$ を $\omega_{1}, \omega_{2} \in U^{*}$ に対し $\omega_{2} \mid \omega_{1}$ とする. $\omega_{2} \mid \omega_{1}$ は入力 $\omega_{1}$ を与えた後すぐに入力 $\omega_{2}$ を与えることを表わす．空な 入力系列を $l$ とし, $|l|=0$ とする.さらに $u \in U, t \in N$ に対し. $u^{t} \in U^{*}$ を $u^{t}(i)=u, 0 \leqq i \leqq t$ と定義する.

出力值集合 $\boldsymbol{Y}$ (出力が取りうる值の集合)を多出力系, すなわち $\boldsymbol{Y}=\boldsymbol{K}^{p}$ として議論することができるが記号 の簡単化のため, $\boldsymbol{Y}=\boldsymbol{K}$ (一出力系) とする. そこで, ブ ラック・ボックスの入出力関係に関してつぎの事実があ $ろ^{4)}$.

\{任意の因果律を満たす入出力写像は入力応答関数 $\alpha$ $\in F\left(U^{*}, \boldsymbol{Y}\right)$ により, $\gamma(|\omega|)=\alpha(\omega), \omega \in U^{*}$ で与えられ る.\}ただし， $\gamma(|\omega|)$ は入力 $\omega$ を入れ終わったときの時刻 $|\omega|$ の出力值を表わす.

本論文ではつぎの定義 (2.1) を満たす入力応答関数を 取り扱う。

\section{（2.1）定義}

入力応答関数 $\alpha \in F\left(U^{*}, Y\right)$ が時不変性：

$$
\alpha\left(\omega_{1} \mid \omega\right)-\alpha\left(\omega_{1}\right)=\alpha\left(\bar{\omega}_{1} \mid \omega\right)-\alpha\left(\bar{\omega}_{1}\right)
$$

を満たすとき， $\alpha$ は時不変入力応答関数といわれる。 ただし任意の $\omega, \omega_{1}, \bar{\omega}_{1} \in U^{*},\left|\omega_{1}\right|=\left|\bar{\omega}_{1}\right|$ である.

(2.2) 定理

時不変入力応答関数 $\alpha \in F\left(U^{*}, \boldsymbol{Y}\right)$ 亿対し関数

$G I: U \rightarrow F(\boldsymbol{N}, \boldsymbol{Y}) ; u \mapsto G I(u)[; t \mapsto$

$$
\left.\alpha\left(u^{t+1}\right)-\alpha\left(u^{t}\right)\right]
$$

が対応しこの対応は全単射である。

（注意）逆対応が次式により与えられることに注目す れば明らかである。

$$
\alpha(\omega)=\alpha(l)+\sum_{j=1}^{|\omega|}\{G I(\omega(j))\}(|\omega|-j)
$$

(2.3) 定義

時不変入力応答関数 $\alpha \in F\left(U^{*}, \boldsymbol{Y}\right)$ に対し定理 (2.2) で与えられる関数

$$
\begin{aligned}
G I: U \rightarrow & F(\boldsymbol{N}, \boldsymbol{Y}) ; u \mapsto G I(u)[; t \mapsto \\
& \left.\alpha\left(u^{t+1}\right)-\alpha\left(u^{t}\right)\right]
\end{aligned}
$$

を $\alpha$ の補正一般インパルス応答という。

(注意) 定理 (2.2)により時不変入力応答関数は補正 一般インパルス応答により特徴づけられることがわか る.

\section{2 擬線形系}

(2.4) 定義

つぎの状態方程式で与えられる系を擬線形系といい, $\sigma=\left((\boldsymbol{X}, F), g, h, h^{0}\right)$ と表わす。

$$
\left(\begin{array}{l}
x(0)=0 \\
x(t+1)=F x(t)+g(\omega(t+1)) \\
\gamma(t)=h^{0}+h x(t)
\end{array}\right.
$$

ただし $\boldsymbol{X}$ は体 $\mathrm{K}$ 上の線形空間であり, $x(t) \in \boldsymbol{X}, F \in$ $L(\boldsymbol{X}), \omega(t) \in U, g \in F(U, \boldsymbol{X}), \gamma(t) \in \boldsymbol{Y}, h^{0} \in \boldsymbol{Y}, h \in$ $L(\boldsymbol{X}, \boldsymbol{Y})$ である.

擬線形系 $\sigma=\left((\boldsymbol{X}, F), g, h, h^{0}\right)$ 亿対し関数

$$
\begin{aligned}
\alpha_{\sigma}: U^{*} \rightarrow & \boldsymbol{Y} ; \omega \mapsto \alpha_{\sigma}(\omega) \\
& =h^{0}+\boldsymbol{h}\left(\sum_{j=1}^{|\omega|} F^{|\omega|-j} g(\omega(j))\right.
\end{aligned}
$$

を $\sigma$ の挙動(behavior) という. 関数

$$
\begin{aligned}
G I_{\sigma}: U & \rightarrow F(\boldsymbol{N}, \boldsymbol{Y}) ; u \\
& \mapsto\left(G I_{\sigma}\right)(u)\left[; \mapsto \boldsymbol{h} F^{t-1} g(u)\right]
\end{aligned}
$$

をのの補正一般インパルス応答という。

時不変入力応答関数 $\alpha \in F\left(U^{*}, \boldsymbol{Y}\right)$ に対し $\alpha_{\sigma}=\alpha$ と なる擬線形系 $\sigma$ は $\alpha$ を実現するという。

$\sigma=\left((\boldsymbol{X}, F), g, h, h^{0}\right)$ を擬線形系とする. 可到達集合 $\left\{\Sigma F^{|\omega|-j} g(\omega(j)) ; \omega \in U^{*}\right\}$ の線形包が $\boldsymbol{X}$ に一致すると き， $\sigma$ は擬可到達であるといわれる。任意の $m \in N$ に対 
し, $h F^{m} x=0$ ならば $x=0$ が成り立つとき, $\sigma$ は可観測 であるといわれる. 擬可到達であり, 可観測である $\sigma$ は 正準系であるといわれる（定義 (2.4) 終わり)

（注意 1） 擬可到達は状態空間 $\boldsymbol{X}$ が入力による影響 を必要最小限もっていることを示し, 可観測は出力から 見て状態空間が最も整理されていることを示す。

(注意 2) 擬線形系 $\sigma$ の挙動 $\alpha_{\sigma}$ と $\sigma$ の補正一般イン パルス応答 $G I_{\sigma}$ とは 1 対 1 に対応する.

(2.5) 定義

$\sigma_{1}=\left(\left(\boldsymbol{X}_{1}, F_{1}\right), g_{1}, h_{1}, h^{0}\right), \sigma^{2}=\left(\left(\boldsymbol{X}_{2}, F_{2}\right), g_{2}, h_{2}, h^{0}\right)$ を擬 線形系とする. $T F_{1}=F_{2} T, T g_{1}=g_{2}$ および $h_{1}=h_{2} T$ を 満たす線形写像 $T: \boldsymbol{X}_{1} \rightarrow \boldsymbol{X}_{2}$ を $\sigma_{1} \rightarrow \sigma_{2}$ の擬線形系射と いう. $T$ が全単射であるとき $T$ を $\sigma_{1} \rightarrow \sigma_{2}$ の同形射とい う.

擬線形系 $\sigma=\left((\boldsymbol{X}, F), g, h, h^{0}\right)$ の状態空間 $\boldsymbol{X}$ が有 限次元 $[n$ 次元 $]$ であるとき， $\sigma$ を有限次元 $[n$ 次元 $]$ 擬線 形系という. $n$ 次元擬線形系は, 一般性を失うことなく, $\sigma=\left(\left(\boldsymbol{K}^{n}, F\right), g, h, h^{0}\right)$ と表わすことができる ${ }^{2)}$. ただし， $F \in K^{n \times n}, h \in \boldsymbol{K}^{1 \times n}$ である。

\section{3. 擬線形系の部分実現問題}

本章以降は入力值集合 $U$ を有限, すなわち $U=\left\{u_{i}\right.$; $1 \leqq i \leqq m\}$ とする.このとき，擬線形系 $\sigma=((\boldsymbol{X}, F), g, h$, $\left.h^{0}\right)$ の写像 $g: U \rightarrow \boldsymbol{K}^{n}$ は $\left\{g\left(u_{i}\right) ; 1 \leqq i \leqq m\right\}$ により完全 に表わされる.この仮定は文献2)で示されたようにそれ ほど特殊な仮定ではない：その例として区分的線形化法 (piecewise-linear method) ${ }^{6), 7}$ により非線形性をもつ電 界効果トランジスタのある電気回路を取り扱えることを

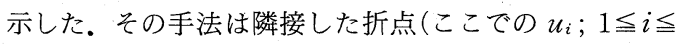
$m$ に相当する)により分割してできる区間ごとに 1 次関 数で近似することにより写像 $g: U \rightarrow K^{n}$ をとえば 写像 $g: \boldsymbol{V} \rightarrow \boldsymbol{K}^{n}$ に拡張しようとするものである.ただ し， $\boldsymbol{V}$ は実数の集合 $\boldsymbol{R}$ のある有界集合である.

この章において, 部分実現問題を論じるのに必要な擬 可到達性预よび可観測性について考察する。そこで, 任 意に与えられた有限長の因果律・時不変性を満たす入出 カデータに対する部分実現問題を論じる.

(3.1) 定義

擬線形系 $\sigma=\left((\boldsymbol{X}, F), g, h, h^{0}\right)$ が

$$
\begin{aligned}
& \boldsymbol{X}=\left\langle\left\{\sum_{j=1}^{|\omega|} \lambda(j, \omega(j)) F^{j-1} g(\omega(j)) ; \lambda(j, \omega(j)) \in \boldsymbol{K},\right.\right. \\
& \left.\omega \in U^{*},|\omega| \leqq p\right\} 》
\end{aligned}
$$

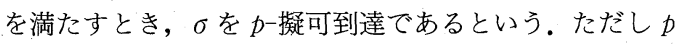
はある正数である.

擬線形系 $\sigma=((\boldsymbol{X}, F), g, h)$ が任意の $t(0 \leqq t \leqq q)$ に対 し $h F^{t} x=0$ ならば $x=0$ が成り立つとき $\sigma$ を $q$-可観測
であるという. ただし $q$ はある正数である.

\section{（3.2）定義}

正の整数 $M$ に対し, 関数 $\underline{\alpha}: U^{*}(\leqq M) \rightarrow Y$ を時不変 入力応答関数 $\alpha: U^{*} \rightarrow Y$ の $U^{*}(\leqq M) へ$ へ制限とする. その時, 関数 $\alpha: U^{*}(\leqq M) \rightarrow Y$ を部分時不変入力応答関 数という. ただし, $U^{*}(\leqq M)=\left\{\omega \in U^{*} ;|\omega| \leqq M\right\}$ であ る.

定理 (2.2)によれば 時不変入力応答関数は同等的に $m$ 個の補正一般インパルス応答 $\left\{G I\left(u_{i}\right) \in F(N, \boldsymbol{Y}) ; 1\right.$ $\leqq i \leqq m\}$ により表わすことができる.

それと同様にして, 部分時不変入力応答関数 $\underline{\alpha} \in$ $F\left(U^{*}(\leqq M), Y\right)$ は同等的に関数 $\underline{G I}\left(u_{i}\right) \in F(\boldsymbol{M}, \boldsymbol{Y}), 1$ $\leqq i \leqq m$ により表わすことができる(定理(2.2)の注を参 照)。それらの対応は次式により与えられる。

$$
(\underline{G I}(u))(t)=\underline{\alpha}\left(u^{t+1}\right)-\underline{\alpha}\left(u^{t}\right),
$$$$
u \in U, 0 \leqq t \leqq M
$$

ただし, $\boldsymbol{M}=\{0,1, \cdots, M\}$ である.

$$
\underline{G I}\left(u_{i}\right) \in F(\boldsymbol{M}, \boldsymbol{Y}), 1 \leqq i \leqq m
$$

を部分補正一般インパルス応答という。

擬線形系 $\sigma=\left((\boldsymbol{X}, F), g, h, h^{0}\right)$ が

$$
h F^{t} g\left(u_{i}\right)=\left(\underline{G I}\left(u_{i}\right)\right)(t), \quad i \leqq i \leqq m
$$

を満たすとき $\sigma$ は部分補正一般インパルス応答 $G I$ を部 分実現するという(定義 (2.4) 参照).

\section{(3.3) 部分実現問題}

与えられた部分補正一般インパルス応答 $G I\left(u_{i}\right) \in F(\boldsymbol{M}$, $\boldsymbol{Y}), 1 \leqq i \leqq m$ に対しそれの最小次元部分実現系を求め, できればそれらが同形を除いて一意であることを示せ。

\section{(3.4) 命題}

任意の部分補正一般インパルス応答 $G I\left(u_{i}\right) \in F(\boldsymbol{M}, \boldsymbol{Y})$, $1 \leqq i \leqq m$ に対し，それを部分実現する有限次元擬線形系 が存在する。したがって $G I\left(u_{i}\right)$ の最小次元部分実現系 が存在する。

（証明） 付録 (B.3) 参照.

部分補正一般インパルス応答の最小次元部分実現系は 一般的に同形の意味でさえも一意ではない.そこで 自然 部分実現系の概念を導入し，自然部分実現系が存在すれ ばそれは最小次元の部分実現系であり，一意であること を示す。

（3.5）定義

部分補正一般インパルス応答 $\underline{G I}\left(u_{i}\right) \in F(\boldsymbol{M}, \boldsymbol{Y}), 1 \leqq$ $i \leqq m$ 扔よび $0 \leqq p+q<M$ を満たす正の整数 $p, q$ に対 し $p$-擬可到達, $q$-可観測となる $\underline{G I}\left(u_{i}\right)$ の部分実現系 $\sigma$ を $G I\left(u_{i}\right)$ の自然部分実現系という.

\section{(3.6) 定義(付録 (A.11) 参照)}

部分時不変入力応答関数 $\underline{\alpha}: U^{*}(\leqq M) \rightarrow Y$ 亿対して つぎの行列 $H_{\alpha(p, M-p)}$ を $\underline{\alpha}$ の有界入出行列という. 
$(s, u)$

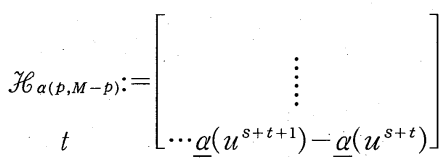

ただし $0 \leqq s \leqq p, 0 \leqq t \leqq M-p, u \in U$ である.

有界入出力行列 $H_{\alpha(p, M-p)}$ の列べクトルを便宜的に $\underline{S_{l}^{s} G I}(u) \in F(\boldsymbol{M}-\boldsymbol{p}, \boldsymbol{Y})$ と表わす.

(3.7) 定理

部分補正一般インパルス応答 $\underline{G I}\left(u_{i}\right) \in F(\boldsymbol{M}, \boldsymbol{Y}), 1 \leqq$ $i \leqq m$ に対する有界入出力行列を $H_{\alpha}$, , とする. そのと き $G I$ の自然部分実現系が存在するための必要十分条件 は $0 \leqq p<M$ を満たすある整数 $p$ に対し

rank $\mathscr{H}_{\alpha(p, M-p)}=$ rank $\mathscr{H}_{\alpha(p, M-p-1)}$

$$
=\operatorname{rank} \mathscr{H}_{\alpha(p+1, M-p-1)}
$$

が成り立つことである。

（証明）付録 (B.8) 参照.

(3.8) 定理

与えられた部分補正一般インパルス応答 $G I\left(u_{i}\right) \in$ $F(\boldsymbol{M} ; \boldsymbol{Y}), 1 \leqq i \leqq m$ の自然部分実現系が存在するため の必要十分条件は $G I\left(u_{i}\right)$ の最小次元の部分実現系が同 形を除いて一意であることである.

（証明） 付録(B.10)参照.

\section{4. 部分実現アルゴリズム}

文献 2)において, 擬可到達標準系を導入し有限次元正 準擬線形系の同形類の代表元として唯一つの擬可到達標 準系があることを示した.さらに与えられた時不変入力 応答関数の無限入出力行列の階数が有限であるとき, 不 変入力応答関数を実現する擬可到達標準系を求める手順 を与えた。この章では, 部分補正一般インパルス応答が 自然部分実現系の条件を満たすとき，それを部分実現す る最小次元擬線形系 (特に擬可到達標準系) を求めるアル ゴリズムを与える。

\section{（4.1）定義}

入力值集合を $U$ を $U:=\left\{u_{j} ; 1 \leqq j \leqq m\right.$ とし, 写像 $\|$

$\|: N \times U \rightarrow N$ を

$$
\left(i, u_{j}\right) \mapsto\left\|\left(i, u_{j}\right)\right\|=m * i+j
$$

と定義し $\left\|\left(i, u_{j}\right)\right\| を\left(i, u_{j}\right) \in N \times U$ の数值という.ここ で, 集合 $N \times U$ に対し, 全順序関係をこの数值により定 義する.すなわち

$$
\left(a, u_{b}\right) \geqq\left(p, u_{q}\right) \Leftrightarrow\left\|\left(a, u_{b}\right)\right\| \geqq\left\|\left(p, u_{q}\right)\right\|
$$
とする。

(4.2) 定理

与えられた部分補正一般インパルス応答 $G I\left(u_{i}\right) \in$ $F(\boldsymbol{M}, \boldsymbol{Y}), 1 \leqq i \leqq m$ が定理 (3.7)の条件を満たすとす
る.そのとき $G I\left(u_{i}\right)$ の自然部分実現系 (擬可到達標準系) $\sigma_{s}=\left(\left(\boldsymbol{K}^{n}, F_{s}\right), g_{s}, h_{s}, h^{0}\right)$

がつぎの手順により得られる。ただし $\underline{G I}\left(u_{i}\right)$ の有界入

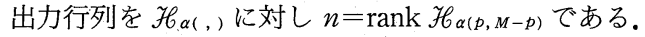

(1) 有界入出力行列 $H_{\alpha(p, M-p)}$ の列べクトル $\left\{\underline{S_{l}^{i}}(G I(u)) ; u \in U, 0 \leqq i \leqq n-1\right\}$ の中から集合 $N \times U$ の数值の順に， 1 次独立ベクトルを選ぶ.

(2)状態空間を $K^{n}$ とする. 写像 $g_{s}: U \rightarrow \boldsymbol{K}^{n}$ を $I_{i}=0$ なる $u_{J i} \in U$ に対し $g_{s}\left(u_{j i}\right):=e_{i}$ とし $\left(0, u_{J i}\right)<\left(0, u_{j}\right)<$ $\left(0, u_{J i+1}\right)$ (または $\left.\left(1, u_{J i+1}\right)\right)$ なる $u_{j} \in U$ に対し

$$
g_{s}\left(u_{j}\right)=\sum_{l=1}^{i} \alpha_{1} e_{1}, \alpha_{1} \in \boldsymbol{K}
$$

とする。

(3)線形写像 $h_{s}: K^{n} \rightarrow Y$ を

$$
\begin{aligned}
h_{s}:= & {\left[\underline{\alpha}\left(u_{J 1}^{I 1+1}\right)-\underline{\alpha}\left(u_{J 1}^{I 1}\right), \underline{\alpha}\left(u_{J 2}^{I 2+1}\right)\right.} \\
& \left.-\underline{\alpha}\left(u_{J 2}^{I 2}\right), \cdots, \underline{\alpha}\left(u_{J n}^{I n+1}\right)-\underline{\alpha}\left(u_{J n}^{I n}\right)\right]
\end{aligned}
$$

とする。

(4) $F_{s}=\left[\boldsymbol{f}^{1}, \boldsymbol{f}^{2}, \quad, \boldsymbol{f}^{n}\right] \in \boldsymbol{K}^{n \times n}, \boldsymbol{f}^{i} \in \boldsymbol{K}^{n}$

$S_{l}^{I i+1} G I(u)=\sum f_{i j} S_{l}^{I j} G I(u)$,

$f_{i j} \in K$ に対し $\boldsymbol{f}^{i}:=\left[f_{i 1}, f_{i 2} \cdots, f_{i n}\right]^{T}$

と定義する。

(5) $h^{0}:=\alpha(l)$ とする.

ただし， $e_{i}:=[00 \cdots 010 \cdots 0]^{T} \in \boldsymbol{K}^{n}, T$ は転置を表わす。

（証明） 付録(C.1)を参照

\section{5. 実時間部分実現アルゴリズム}

第 4 章において 理想的な(多重実験により得られる有 限個の入出力データに基づく)部分実現問題を論じた。一 般的に, 非線形系の部分実現問題を解くには多重実験が 要求される.この章では 4 章の成果に基づいて単一実験 による部分実現問題(実時間部分実現問題)を論じる。し たがって多重実験により得られた入出力データと同じ 効果をもたらす単一実験による入出力デー夕を得ること を目的とする。

\section{（5.1）実時間部分実現問題}

考察対象である時不変入力応答関数 $\alpha \in F\left(U^{*}, \boldsymbol{Y}\right)$ が 有限次元擬線形系の挙動であるとする. そのとき時不変 入力応答関数 $\alpha$ および単一実験である有限個の入出力 デー夕 $\left\{\alpha(\underline{\omega}) \in \boldsymbol{Y}\right.$; ある有限長の入力 $\left.\underline{\omega} \in U^{*}\right\}$ に対し

$$
\alpha_{\sigma}(\omega)=\alpha(\omega),{ }^{\forall} \omega \in U^{*}
$$

となる正準擬線形系 $\sigma=\left((\boldsymbol{X}, F), g, h, h^{0}\right)$ および有限長 の入力 $\omega \in U^{*}$ を求めよ.

(5.2) 定義

考察対象である有限次元擬線形系に対し，実時間部分 実現問題の解が存在するときの入力 $\underline{\omega} \in U^{*}$ を(実時間 部分)実現信号という. 
（注意） 実現信号 $\underline{\omega} \in U^{*}$ は，単一実験であるが見掛 け上の多重実験の効果をもたらす。

(5.3) 補題

与えられた時不変入力応答関数 $\alpha \in F\left(U^{*}, \boldsymbol{Y}\right)$ が $L$ 次元以下の擬線形系の挙動であると仮定する. そのとき ときつぎの手順により有界入出力行列 $H_{\alpha(L-1, p)}$ が得ら れる入力 $\underline{\omega} \in U^{*}$ が存在する. ただし $P=\max \left\{L_{1}, L_{2}\right.$, $\left.\cdots, L_{m}\right\}$ である.

1) 列ベクトル $\left\{S_{l}^{i} G I\left(u_{1}\right) \in \boldsymbol{K}^{L-1} ; 0 \leqq i \leqq L_{1}-1\right\}$ が 一次独立であり $\left\{\underline{S_{l}^{i} G I}\left(u_{i}\right) \in \boldsymbol{K}^{L-1} ; 0 \leqq i \leqq L_{1}\right\}$ が一次従 属となる整数 $L_{1}$ を見いだす. すなわち, 入力 $\omega_{1}=u_{1}^{L 1+L}$ を加える。

2) 今までの入力 $\omega_{1}$ に入力 $\omega_{2}:=u_{1}^{L 2+L-1} \mid u_{2}$ を付け加 えて, 列べクトル $\left\{\underline{S_{l}^{i} G I}\left(u_{j}\right) \in \boldsymbol{K}^{L-1} ; 0 \leqq i \leqq L_{j}-1,1 \leqq j\right.$ $\leqq 2\}$ が 1 次独立であり $\left\{\underline{S_{l}^{i} G I}\left(u_{j}\right), \underline{S_{l}^{L 2} G I}\left(u_{2}\right) \in \boldsymbol{K}^{L-1} ; 0\right.$ $\left.\leqq i \leqq L_{j}-1,1 \leqq j \leqq 2\right\}$ が 1 次従属となる整数 $L_{2}$ を見い だす。

3) 今までの入力 $\omega_{2} \mid \omega_{1}$ に入力 $\omega_{3}:=u_{1}^{L 3+L-1} \mid u_{3}$ を付 け加えて列べクトル $\left\{\underline{S_{l}^{i} G I}\left(u_{j}\right) \in \boldsymbol{K}^{L-1} ; 0 \leqq i \leqq L_{j}-1,1\right.$ $\leqq j \leqq 3\}$ が一次独立であり $\left\{\underline{S_{l}^{i} G I}\left(u_{j}\right), \underline{S}_{l}^{L_{3}} G I\left(u_{3}\right) \in\right.$ $\left.\boldsymbol{K}^{L-1} ; 0 \leqq i \leqq L_{j}-1,1 \leqq j \leqq 3\right\}$ が一次従属となる整数 $L_{3}$ を見いだす。

$m)$ 今までの入力 $\omega_{m-1}|\cdots| \omega_{2} \mid \omega_{1}$ に入力 $\omega_{m}:=$ $u_{1}^{L m+L-1} \mid u_{m}$ を付け加えて, 列べクトル $\left\{\underline{\left\{S_{l}^{i} G I\right.}\left(u_{j}\right) \in\right.$ $\left.\boldsymbol{K}^{L-1} ; 0 \leqq i \leqq L_{j}-1,1 \leqq j \leqq m\right\}$ が一次独立であり $\left\{\underline{S_{l}^{i} G I}\left(u_{j}\right), \underline{S_{l}^{L m} G I}\left(u_{m}\right) \in \boldsymbol{K}^{L-1} ; 0 \leqq i \leqq L_{j}-1,1 \leqq j \leqq m\right\}$ が一次従属となる整数 $L_{m}$ を見いだす. $\underline{\omega}=$ $\omega_{m}\left|\omega_{m-1}\right| \cdots\left|\omega_{2}\right| \omega_{1}$ とする.

$m+1)$ 以上により得られた列べクトル $\left\{\underline{S_{l}^{i} G I}\left(u_{j}\right) \in\right.$ $\left.\boldsymbol{K}^{L-1} ; 0 \leqq i \leqq L_{j}-1,1 \leqq j \leqq m\right\}$ を列ベクトルとして有界 入出力行列 $\mathscr{H}_{\alpha(L-1, p)}$ が得られる.

（証明），付録(C.2) を参照.

(5.4) 定理

与えられた時不変入力応答関数 $\alpha \in F\left(U^{*}, \boldsymbol{Y}\right)$ が $L$ 次元以下の擬線形系の挙動であると仮定する. そのとき $\alpha$ を実現する正準擬線形系 $\sigma_{s}=\left(\left(\boldsymbol{K}^{n}, F_{s}\right), g_{s}, h_{s}, h^{0}\right)$ を 求める実現信号 $\underline{\omega} \in U^{*}$ が存在し， $\sigma_{s}$ はつぎのようにし て得られる。. [補題(5.3)で得られた有界入出力行列 $\mathscr{H}_{\alpha(p, L-1)}$ に対して, 定理 (4.2)での部分実現アルゴリズ ムを適用する.]ただし $p:=\max L_{i}$ である.

(証明) 定理 $[4.2]$, 補題 $[5.3]$ より明らかである.

\section{6. おわりに}

われわれは離散時間非線形系の因果律および時不変を 満たすブラック・ボックスの入出力写像 (同等的に, 時不
変入力応答関数)に対する擬線形系による部分実現およ び実時間部分実現問題を提起し，つぎの主な成果を得た。

1) 任意に与えられた有限長の入出力デー夕(同等的 に部分補正一般インパルス応答 $G I) に$ 対し $\underline{G I}$ を部分 実現する最小次元擬線形系が必ず存在する.

2）部分補正一般インパルス応答関数 $G I$ に対し，自 然部分実現系なる概念を導入し， $G I$ の自然部分実現系 が存在するための必要十分条件が $G I$ の有界入出力行列 の階数により与えられる。

3）部分補正一般インパルス応答 $G I$ の自然部分実現 系の存在条件と $G I$ の最小次元部分実現系が一意である ことと同等である。

4）与えられた部分補正一般インパルス応答 $G I$ から GI の自然部分実現系を求めるアルゴリズムの導出.

さらに，これらの理想的な(多重実験による)部分実現 問題の成果を基につぎの単一実験に関する成果を得た。

5）因果律および時不変を満たすブラック・ボックス の入出力写像が有限次元擬線形系で表わせると仮定す る.そのとき，その最小次元部分実現系を得る実現信号 (入力系列)が存在する.

本論文の部分実現理論は定係数線形系の部分実現理論 体系の擬線形系への拡張であることは容易にわかる ${ }^{3)}$. 非線形系にもかかわらず実時間部分実現問題が取扱い可 能となったのは対象のブラック・ボックスを補正一般イ ンパルス応答関数により記述できたことと時不変性によ る. 本論文の影響は大きい.たとえば，擬線形系のサブ クラスの系として概線形系がある7). その概線形系の具 体例として “いわゆる” 線形系 (初期状態が零でない線形 系)がある7)、本論文の実時間部分実現理論をその系に適 用すれば, 従来の線形系の部分実現問題と未知の状態を 既知とする推定問題との二つの問題が一つの“いわゆる” 線形系の実時間部分実現問題として考えられ，その系が 実時間(単一実験)により決定できることを示唆する.

\section{参 考 文 献}

.1）長谷川，松尾：離散時間・擬線形系の実現理論, 計測自動 制御学会論文集, 28-2, 199/207（1992）

2) 長谷川, 松尾：離散時間・有限次元擬線形系の実現理論, 計 測自動制御学会論文集, 29-9, 1072/1080（1993）

3) R.E. Kalman et al. : Topics in Mathematical System Theory, McGraw-Hill (1969)

4) T. Matsuo: Realization Theory of Continuous Time Dynamical Systems, Lecture Notes in Control \& Information Sciences, 32, Springer-Verlag (1981)

5) L. O. Chua: Introduction to Nonlinear Network Theory, McGraw-Hill (1969)

6) 牛田, 森：非線形回路の数值解析法, 森北出版 (1987)

7）松尾, 長谷川：離散時間・概線形系の実時間部分実現理論, 第 35 回自動制御連合講演会前刷, 71/72（1992） 
《付 録 A》

付録 B に必要な事柄を文献 1)，2）加抽出する.

（A.1）定義

擬線形系 $\sigma=\left((\boldsymbol{X}, F), g, h, h^{0}\right)$ に対し 対 $(\boldsymbol{X}, F)$ を自 由運動といい, 組 $((\boldsymbol{X}, F), g)$ を入力写像付き自由運動 という.さらに組 $((X, F), h)$ を出力機構付自由運動と いう.

(A.2) 擬線形系の例

$A(\boldsymbol{N} \times U, \boldsymbol{K}):=$ 関数 $\lambda: \boldsymbol{N} \times U \rightarrow \boldsymbol{K} ; \lambda=\Sigma \lambda(n$, $u) e_{(n, u)}$ (有限個の和), $\left.n \in \boldsymbol{N}, u \in U, \lambda(n, u) \in \boldsymbol{K}\right\}$.

ただし $e_{(n, u)}$ は次式により与えられる。 $m, n \in N, u$, $u^{\prime} \in U$ に対乙

$$
e_{(n, u)}^{\prime}\left(m, u^{\prime}\right)=1\left(m=n, u^{\prime}=u\right. \text { のときのみ), }
$$$$
e_{(n, u)}\left(m, u^{\prime}\right)=0\left(m \neq n \text { または } u^{\prime} \neq u \text { のとき }\right) \text {. }
$$

そのとき, $A(\boldsymbol{N} \times U, \boldsymbol{K})$ は線形空間である. $A(\boldsymbol{N} \times U$, $\boldsymbol{K})$ の基底 $\left\{\boldsymbol{e}_{(n, u)}: n \in \mathbb{N}, u \in U\right\}$ に対し $S_{r}$ を

$S_{r} e_{(n, u)}=e_{(n+1, u)}$

とすれば $S_{r} \in L(A(\boldsymbol{N} \times U, \boldsymbol{K}))$ である.したがって，対 $\left(A(\boldsymbol{N} \times U, \boldsymbol{K}), S_{r}\right)$ は自由運動である. 写像 $\eta:$ $U \rightarrow A(\boldsymbol{N} \times U, \boldsymbol{K})$ を任意の $u \in U$ に対し $\eta(u):=e_{(0, u)}$ と定義する。任意の時不変入力応答関数 $\alpha \in F_{s}\left(U^{*}, Y\right)$ に対し線形写像 $\underline{\boldsymbol{a}}: A(\boldsymbol{N} \times U, \boldsymbol{K}) \rightarrow \boldsymbol{Y}$ を次式により定 義する。

$$
\underline{\boldsymbol{a}}\left(e_{(n, u)}\right)=\alpha\left(u^{n+1}\right)-\alpha\left(u^{n}\right)
$$

ただし $e_{(n, u)} \in A(\boldsymbol{N} \times U, \boldsymbol{K})$ であり， $u^{0}:=l$ である.

そこで組

$$
\sigma=\left(\left(A(\boldsymbol{N} \times U, \boldsymbol{K}), S_{r}\right), \boldsymbol{\eta}, \underline{\boldsymbol{a}}, \alpha(l)\right)
$$

は $\alpha$ を実現する擬可到達な擬線形系である.

(A.3) 擬線形系の例

$F(\boldsymbol{N}, \boldsymbol{Y}):=\{$ 関数 $f: \boldsymbol{N} \rightarrow \boldsymbol{Y}\}, \boldsymbol{\gamma} \in F(\boldsymbol{N}, \boldsymbol{Y}), t \in \boldsymbol{N}$ 亿対 し $\left(S_{l} \gamma\right)(t):=\gamma(t+1)$ と定義すれば $S_{l} \in L(F(\boldsymbol{N}, \boldsymbol{Y}))$ で あり, 対 $\left(F(\boldsymbol{N}, \boldsymbol{Y}), S_{l}\right)$ は自由運動である。 $\alpha \in F\left(U^{*}\right.$, $Y)$ を任意の時不変入力応答関数とする.ここで 写像

$\zeta: U \rightarrow F(\boldsymbol{N}, \boldsymbol{Y})$ を $u \in U, t \in \boldsymbol{N}$ に対し

$$
(\boldsymbol{\zeta}(u))(t)=\alpha(\omega \mid u)-\alpha(\omega)
$$

により定義する。ただし $\omega$ は長さ $t$ の任意の入力であ る.さらに線形写像 0: $F(\boldsymbol{N}, \boldsymbol{Y}) \rightarrow \boldsymbol{Y}$ を $\gamma \mapsto \gamma(0)$ により 定義する。そここで組

$$
\sigma=\left(\left(F(\boldsymbol{N}, \boldsymbol{Y}), S_{l}\right), \boldsymbol{\zeta}, 0, \alpha(l)\right)
$$

は $\alpha$ を実現する可観測な擬線形系である.

\section{(A.4) 定義}

$\left(\boldsymbol{X}_{1}, F_{1}\right),\left(\boldsymbol{X}_{2}, F_{2}\right)$ を自由運動とする. $T F_{1}=F_{2} T$ を満 たす線形写像 $T: \boldsymbol{X}_{1} \rightarrow \boldsymbol{X}_{2}$ を $\left(\boldsymbol{X}_{1}, F_{1}\right) \rightarrow\left(\boldsymbol{X}_{2}, F_{2}\right)$ の自由 運動射という。

$g_{1}, g_{2} \in F(U, \boldsymbol{X})$ に対し $T g_{1}=g_{2}$ を満たす自由運動射
$T:\left(\boldsymbol{X}_{1}, F_{1}\right) \rightarrow\left(\boldsymbol{X}_{2}, F_{2}\right)$ を $\left(\left(\boldsymbol{X}_{1}, F_{1}\right), g_{1}\right) \rightarrow\left(\left(\boldsymbol{X}_{2}, F_{2}\right), g_{2}\right)$ の 入力写像付自由運動射という。

線形出力機構 $h_{1}, h_{2} \in L(X, Y)$ に対し $h_{1}=h_{2} T$ を満 たす自由運動射 $T:\left(\boldsymbol{X}_{1}, F_{1}\right) \rightarrow\left(\boldsymbol{X}_{2}, F_{2}\right)$ を $\left(\left(\boldsymbol{X}_{1}, F_{1}\right)\right.$, $\left.h_{1}\right) \rightarrow\left(\left(\boldsymbol{X}_{2}, F_{2}\right), h_{2}\right)$ の出力 (機構) 付自由運動射という.

(A.5) 補題

$\sigma_{1}=\left(\left(\boldsymbol{X}_{1}, F_{1}\right), g_{1}, h_{1}, h^{0}\right), \sigma_{2}=\left(\left(\boldsymbol{X}_{2}, F_{2}\right), g_{2}, h_{2}, h^{0}\right)$ を擬 線形系とし，Tを $\sigma_{1} \rightarrow \sigma_{2}$ の擬線形系射とする。そのとき $\sigma_{1}$ の挙動 $\alpha_{\sigma 1}$ と $\sigma_{2}$ の挙動 $\alpha_{\sigma 2}$ とは等しい.

(A.6) 定義

擬線形系 $\sigma=\left((\boldsymbol{X}, F), g, h, h^{0}\right)$ に対し線形写像

$$
\boldsymbol{G}: A(\boldsymbol{N} \times U, \boldsymbol{K}) \rightarrow \boldsymbol{X} ; e_{(n, u)} \rightarrow F^{n} g(u)
$$

は自由運動射 $\boldsymbol{G}:\left(A(\boldsymbol{N} \times U, \boldsymbol{K}), S_{r}\right) \rightarrow(\boldsymbol{X}, F)$ であり, $\boldsymbol{G}$ は $g$ に対応する線形入力写像といわれ, 線形写像

$H: \boldsymbol{X} \rightarrow F(N, \boldsymbol{Y}) ; \boldsymbol{x} \mapsto H \boldsymbol{x}\left[t \mapsto h F^{t} \boldsymbol{k}\right]$

は自由運動射 $H:(\boldsymbol{X}, F) \rightarrow\left(F(\boldsymbol{N}, \boldsymbol{Y}), S_{l}\right)$ であり, $H$ は $h$ に対応する線形観測写像といわれる。

特に自由運動射

$$
A:\left(A(\boldsymbol{N} \times U, \boldsymbol{K}), S_{r}\right) \rightarrow\left(F(\boldsymbol{N}, Y), S_{l}\right)
$$

は線形入出力写像といわれる.

\section{(A.7) 命題}

任意の入力写像付き自由運動 $((X, F), g)$ に対し, 線 形入力写像 $\boldsymbol{G}:\left(A(\boldsymbol{N} \times U, \boldsymbol{K}), S_{r}\right) \rightarrow(\boldsymbol{X}, F)$ が唯一つ 対応し, $g(u)=\boldsymbol{G}\left(e_{(0, u)}\right)$ によりこの対応は全単射であ る. 任意の出力機構付き自由運動 $((X, F), h)$ 亿対し, 線 形観測写像 $\boldsymbol{H}:(\boldsymbol{X}, F) \rightarrow\left(F(\boldsymbol{N}, \boldsymbol{Y}), S_{l}\right)$ が唯一つ対応 し, $h=0 \cdot \boldsymbol{H}$ によりこの対応は全単射である.

\section{(A.8) 補題}

任意の線形入出力写像

$$
\boldsymbol{A}:\left(A(\boldsymbol{N} \times U, \boldsymbol{K}), S_{r}\right) \rightarrow\left(F(\boldsymbol{N}, \boldsymbol{Y}), S_{l}\right)
$$

に対し時不変入力応答関数 $\alpha \in F\left(U^{*}, \boldsymbol{Y}\right)$ が次式により 対応しこの対応は全単射である。

$$
\alpha\left(u^{s+t+1}\right)-\alpha\left(u^{s+t}\right)=\left(A\left(e_{(s, u)}\right)\right)(t)
$$

ただし $s, t \in N, u \in U$ である

ある正数 $p$ に対し， $\left\langle A(N \times U, \boldsymbol{K})_{p}\right\rangle:=\{\Sigma \lambda(q$, $\left.u) e_{(q, u)} \in A(\boldsymbol{N} \times U, \boldsymbol{K}), q \leqq p\right\}$ とし, 写像 $J_{p}: 《 A(\boldsymbol{N} \times$ $U, \boldsymbol{K})_{p} 》 \rightarrow A(\boldsymbol{N} \times U, \boldsymbol{K})$ を標準的単射とする.

(A.9) 定義

入力写像付き自由運動 $((X, F), g)$ が

$$
\begin{aligned}
\boldsymbol{X}= & 《\left\{\sum_{j=1}^{|\omega|} \lambda(j, \omega(j)) F^{j-1} g(\omega(j)) ;\right. \\
& \lambda(j, \omega(j)) \in \boldsymbol{K}, \omega \in U^{*},|\omega| \leqq p 》
\end{aligned}
$$

を満たすとき， $((\boldsymbol{X}, F), g)$ を $p$-擬可到達であるという. (注意) $((\boldsymbol{X}, F), g)$ は $p$-擬可到達であることと写像 $\boldsymbol{G}_{p}:=\boldsymbol{G} \cdot J_{p}:\left\langle A(\boldsymbol{N} \times U, \boldsymbol{K})_{p}\right\rangle \rightarrow \boldsymbol{X}$ が全射であること と同等である.ただし, $G$ は $((X, F), g)$ に対応する線形 
入力写像である.

ある正数 $q$ に対し $q=\{0,1, \cdots, q\}$ とし, $P_{q}: F(\boldsymbol{N}$, $\boldsymbol{Y}) \rightarrow F(\boldsymbol{q}, \boldsymbol{Y})$ を標準的全射とする.また, $S_{l}$ を次式によ り定義する。

$\underline{S_{l}}: F(\boldsymbol{q}, \boldsymbol{Y}) \rightarrow F(\boldsymbol{q}-\mathbf{1}, \boldsymbol{Y}) ; \gamma \mapsto \underline{S_{l}} \gamma[t \mapsto \gamma(t+1)]$

(A.10) 定義

出力機構付自由運動 $((\boldsymbol{X}, F), g, h)$ が任意の $t(0 \leqq t$ $\leqq q)$ に対し $h F^{t} x=0$ ならば $x=0$ が成り立つとき $((\boldsymbol{X}$, $F), g, h)$ を $q$-可観測であるという.

（注意） $((\boldsymbol{X}, F), g, h)$ が $q$-可観測であることと線形 写像 $\boldsymbol{H}_{q}:=P_{q} \boldsymbol{H}: \boldsymbol{X} \rightarrow F(\boldsymbol{q}, \boldsymbol{Y})$ が単射であることと同 等である.ただし $H$ は $((\boldsymbol{X}, F), h)$ に対応する線形観測 写像 $\boldsymbol{H}:(\boldsymbol{X}, F) \rightarrow\left(F(\boldsymbol{N}, \boldsymbol{Y}), S_{l}\right)$ である.

(A.11) 有界入出行列の導出

文献 1) において (補題 (A.8) 参照), 時不変入力応答関 数 $\alpha \in F\left(U^{*}, \boldsymbol{Y}\right)$ に対し線形入出力写像

$$
\begin{aligned}
& \boldsymbol{A}:\left(A(\boldsymbol{N} \times U, \boldsymbol{K}), S_{r}\right) \rightarrow\left(F(\boldsymbol{N}, \boldsymbol{Y}), S_{l}\right), \\
& \therefore\left(\boldsymbol{A}\left(e_{(s, u)}\right)\right)(t)=\alpha\left(u^{s+t+1}\right)-\alpha\left(u^{s+t}\right)
\end{aligned}
$$

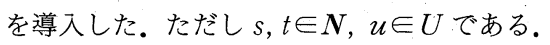

それと同様にして部分時不変入力応答関数 $\underline{\alpha}: U^{*}$ $(\leqq M) \rightarrow Y$ に対して部分線形入出力写像

$$
\begin{aligned}
\boldsymbol{A}_{p, M-p}: & 《 A(\boldsymbol{N} \times U, \boldsymbol{K})_{p} 》 \rightarrow(F(\boldsymbol{M}-\boldsymbol{p}, \boldsymbol{Y}) ; \\
e_{(s, u)} \mapsto \boldsymbol{A}_{p, M-p}\left(e_{(s . u)}\right)[; t \mapsto & \\
& \left.\underline{\alpha}\left(u^{s+t+1}\right)-\underline{\alpha}\left(u^{s+t}\right)\right]
\end{aligned}
$$

を考えることができる.その $\boldsymbol{A}_{p, M-p}$ は

$$
\boldsymbol{A}_{p, M-p}:=P_{M-p} \cdot \boldsymbol{A} \cdot J_{p}
$$

で与えられる。

その $\boldsymbol{A}_{p, M-p}$ の行列表現が $\alpha$ の有界入出行列 $\mathscr{H}_{\alpha(p, M-p)}$ となる。

\section{《付録 $\mathbf{B}$ 》}

この付録で第 3 章の証明を行う.記号】は「証明終わり」 を表わす。

(B.1) 命題

《A $\left.(\boldsymbol{N} \times U, \boldsymbol{K})_{p+1}\right\rangle$ 部分空間 $S$ がつぎの条件を満た すとする.

1) $\lambda \in 《 A(\boldsymbol{N} \times U, \boldsymbol{K})_{p} 》 \cap S$ ならば, $S_{r} \lambda \in S$ が成り 立つ.

2) 任意の $u \in U$ に対し

$e_{(n+1, u)}-\sum \lambda\left(q, u^{\prime}\right) e_{\left(q, u^{\prime}\right)} \in S$

となる $\lambda\left(q, u^{\prime}\right) \in \boldsymbol{K}, 0 \leqq q \leqq p$ が存在する.

そのとき, $\left.S \cap 《 A(\boldsymbol{N} \times U, \boldsymbol{K})_{p+1}\right\rangle=S$ となり $\| A(\boldsymbol{N} \times$ $\left.U, \boldsymbol{K})_{p+1}\right\rangle / S$ と $A(\boldsymbol{N} \times U, \boldsymbol{K}) / \underline{S}$ とが線形空間として同 形となる $S_{r}$ に関しての不変部分空間 $\underline{S} \subset A(\boldsymbol{N} \times U, \boldsymbol{K})$ が唯一つ存在する.さらに入力写像付き自由運動 $((A)$ $\left.\left.\times U(\underline{S}, \boldsymbol{K}), \underline{S_{r}}\right), \underline{\bar{\eta}}\right)$ は $p$-擬可到達である.ただし, $\underline{\eta}(u)$ $=e_{(0, u)}+\underline{S},{ }^{\forall} u \in U$ であり,$\underline{S_{r}}(\lambda+\underline{S})=S_{r} \lambda+\underline{S}$ であ る.

(証明) $J_{p, p+1}: 《 A(N \times U, K)_{p} 》 \rightarrow 《 A(\boldsymbol{N} \times U$, $\boldsymbol{K})_{p+1} 》 を$ 標準的単射とし, $\Pi_{s}:\left\langle A(\boldsymbol{N} \times U, \boldsymbol{K})_{p+1}\right\rangle \rightarrow$ $\left\langle A(\boldsymbol{N} \times U, \boldsymbol{K})_{p+1}\right\rangle / S ; \lambda \mapsto \lambda+S$ を標準的全射とする. そのとき条件 2$)$ により $\Pi_{s} \cdot J_{p, p+1}$ は全射である。また, 条件 1)により任意の $\lambda \in S$ に対し $S_{r} \lambda \in S$ が成り立つ. したがって $\underline{S_{r}}(\lambda+S):=S_{r} \lambda+S,{ }^{\forall} \lambda \in 《 A(\boldsymbol{N} \times U, \boldsymbol{K})_{p} 》$ により $\underline{S_{r}} \in L\left(《 A(\boldsymbol{N} \times U, \boldsymbol{K})_{p+1} 》\right)$ が一意に定義できて $\left.\left(\left(《 A(\boldsymbol{N} \times U, \boldsymbol{K})_{p+1}\right\rangle / S, \underline{S_{r}}\right), \hat{\eta}\right)$ は入力写像付自由運動 となり $p$-擬可到達である.ただし， $\hat{\eta}(u):=e_{(0, u)}+S$ で ある. $\left.\left(\left(《 A(\boldsymbol{N} \times U, \boldsymbol{K})_{p+1}\right\rangle / S, \underline{S_{r}}\right), \hat{\eta}\right)$ に対応する線形入 力写像 $\boldsymbol{G}:\left(A(\boldsymbol{N} \times U, \boldsymbol{K}), S_{r}\right) \rightarrow\left(《 A(\boldsymbol{N} \times U, \boldsymbol{K})_{p+1} 》\right.$ $\left./ S, \overline{S_{r}}\right)$ は命題 $(\mathrm{A} .7)$ により一意である. $\boldsymbol{G}_{p+1}:=\boldsymbol{G} \cdot J_{p+1}$ とすれば ker $\boldsymbol{G}_{p+1}=S$ であり $\underline{S}:=\operatorname{ker} \boldsymbol{G}$ は $\underline{S} \cap 《 A(\boldsymbol{N} \times$ $\left.U, \boldsymbol{K})_{p+1}\right\rangle=S$ を満たし $\boldsymbol{G}$ が線形入力写像であること から $\underline{S}$ は $S_{r}$ に関しての不変部分空間である.さらに $\boldsymbol{G}$ が全射であるから $\left.\left(\left(《 A(N \times U, \boldsymbol{K})_{p+1}\right\rangle / S, \underline{S_{r}}\right), \hat{\eta}\right)$ と $\left(\left(A(\boldsymbol{N} \times U, \boldsymbol{K}) / \underline{S}, \dot{S}_{r}\right), \underline{\tilde{\eta}}\right)$ とは同形である. 従って $\left(\left(A(\boldsymbol{N} \times U, \boldsymbol{K}) / \underline{S}, \dot{S}_{r}\right), \underline{\underline{\eta}}\right)$ は $p$-擬可到達である. $\underline{S}$ の 一意性は $\underline{S_{r}}$ と $\boldsymbol{G}$ の一意性による.

(B.2) 命題

$F(\boldsymbol{q}+\mathbf{1}, \boldsymbol{Y})$ の部分空間 $Z$ がつぎの条件を満たすとす る.

1) 合成写像 $\pi \cdot j: Z \rightarrow F(\boldsymbol{q}+\mathbf{1}, \boldsymbol{Y}) \rightarrow F(\boldsymbol{q}, \boldsymbol{Y})$ が単 射である.ただし, $j$ は標準的単射であり, $\pi$ は標準的全 射である.

2) $\operatorname{im}\left(\underline{S_{l}} \cdot j\right) \subseteq \operatorname{im}(\pi \cdot j)$ が $F(\boldsymbol{q}, \boldsymbol{Y})$ において成り立 つ. そのとき, 写像 $\left.P_{q}\right|_{x}: X \rightarrow Z$ が全射となる自由運動 $\left(\boldsymbol{X}, S_{l}\right)$ が唯一つ存在する. さらに, 出力機構付自由運動 $\left.\left(\boldsymbol{X}, S_{l}\right), 0\right)$ は $q$-可観測である.

ただし, $\left.P_{q}\right|_{x}$ は標準的全射 $P_{q}: F(\boldsymbol{N}, \boldsymbol{Y}) \rightarrow F(\boldsymbol{q}, \boldsymbol{Y})$ の $\boldsymbol{X}$ への制限である.

(証明) 条件 1)，2）により任意の $z \in Z$ に対し $F z=$ $(\pi \cdot j)^{-1} \underline{S_{l}} j(z)$ が定義できて $F \in L(Z)$ となる. したがっ て $(Z, F)$ は自由運動である. 線形写像 $0: Z \rightarrow Y ; \gamma \mapsto$ $\gamma(0)$ により $((Z, F), 0)$ は可観測な出力機構付き自由運 動であり, 写像 $\pi \cdot j: Z \rightarrow F(\boldsymbol{q}, \boldsymbol{Y})$ が単射であるから $((Z, F), 0)$ は $q$-可観測である.

$((Z, F), 0)$ に対応する線形観測写像: $(Z, F) \rightarrow(F(N$, $\left.\boldsymbol{Y}), S_{l}\right)$ を $\boldsymbol{H}$ とすれば命題 $(\mathrm{A} .7)$ により $0=0 \cdot \boldsymbol{H}$ であ り, 文献 1)の命題 (5.8)により $H$ は単射である.ここで, $X:=\operatorname{im} H$ とすれば $\left(\left(X, S_{l}\right), 0\right)$ と $((Z, F), 0)$ とは出力 機構付き自由運動として同形である.ゆえに $\left(\left(X, S_{l}\right), 0\right)$ は $q$-可観測である. なお, 線形写像 $\boldsymbol{H}^{-1}: X \rightarrow Z$ は明ら かに標準的全射 $P_{q}: F(N, \boldsymbol{Y}) \rightarrow F(\boldsymbol{q}, \boldsymbol{Y})$ の $X$ への制 
限 $\left.P_{q}\right|_{x}$ である. $X$ の一意性は $F$ および線形観測写像 $H$ の一意性から得られる。

(B.3) 命題 (3.4)の証明

任意の $u \in U, t \in M=\{0,1, \cdots, M\}$ に対し $(G I(u))(t)$ $=(G I(u))(t)$ とし $t \in \boldsymbol{N} \backslash \boldsymbol{M}$ に対し $(G I(u))(t)=0$ とす

る. すなわち部分時不変入力応答関数 $\alpha \in F\left(U^{*}(\leqq M)\right.$, $Y) に$ 対し $\alpha\left(u^{t+1}\right)=\underline{\alpha}\left(u^{t+1}\right),{ }^{\vee} u \in U,{ }^{\vee} 0 \leqq t \leqq M$ とし, $\alpha\left(u^{t+1}\right)=\alpha\left(u^{t}\right),{ }^{\forall} u \in U,{ }^{\forall} t>M$ として時不変入力応答 関数 $\alpha \in F\left(U^{*}, \boldsymbol{Y}\right)$ を定める. そのとき $S_{i}^{i}(\zeta(u))(t)=$ $\alpha\left(u^{t+i+1}\right)-\alpha\left(u^{t+i}\right)=S_{i}^{i}(G I(u))(t), i, t \in N$ が 成り立 つ. $G I($ 同等的に $\alpha$ )の決め方により線形空間

$$
\left.《\left\{S_{i}^{i} \zeta(u) ; i \in N, u \in U\right\}\right\rangle=: W
$$

は有限次元である.ゆえに組

$$
\sigma=\left(\left(W, S_{l}\right), \zeta, O, \alpha(l)\right)
$$

は $\alpha$ を実現する有限次元擬線形系である.したがって $\underline{G I}$ (同等的に $\underline{\alpha}$ ) を部分実現する有限次元擬線形系が存 在する.ゆえに最小次元部分実現系が存在する。(証明終)

つぎの補題の可換図は明らかである.

(B.4) 補題

部分補正一般インパルス応答関数 $\underline{G I}\left(u_{i}\right) \in F(\boldsymbol{M}, \boldsymbol{Y})$, $1 \leqq i \leqq m$ (同等的に 部分時不変入力応答関数 $\underline{\alpha} \in F$ $\left(U^{*}(\leqq M), Y\right)$ に対応する部分線形入出力写像を $A_{(,)}$ とする.そのときつぎの 1)，2）の図が可換である. ただし, ${ }^{\forall} p<M$.

1)

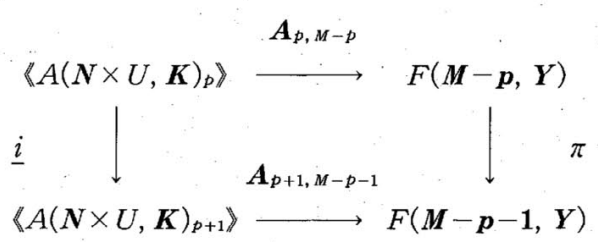

ただし $i$ は標準的単射であり， $\pi$ は標準的全射である。

2)

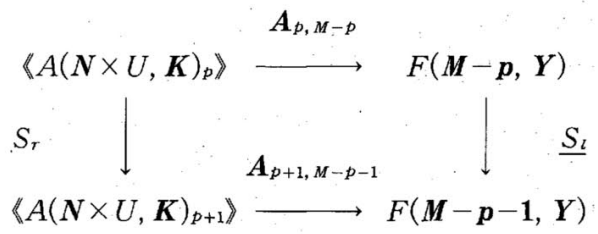

(B.5) 命題

部分補正一般インパルス応答 $G I\left(u_{i}\right) \in F(\boldsymbol{M}, \boldsymbol{Y}), 1 \leqq$ $i \leqq m$ に対応する部分線形入出力写像を $A_{(,)}$, とする. そ のとき $0 \leqq p_{2} \leqq p_{1} \leqq M$ を満たす整数 $p_{1}, p_{2}$ に対し im $\boldsymbol{A}_{p 2+1}$, ${ }_{M-p 2-1}=\operatorname{im} A_{p 2, M-p 2-1}$ ならぱ $\operatorname{im} \boldsymbol{A}_{p 1, M-p 1}=\operatorname{im} A_{p 2}$, $M-p 1$ が成り立つ.

(証明) 部分補正一般インパルス応答関数 $G I$ に対応 する部分時不変入力応答関数を $\underline{\alpha}$ とする. $0 \leqq n \leqq M-p_{2}$
-1 を満たす任意の整数 $n$ に対し im $A_{p 2+1, M-p 2-1}=\mathrm{im}$ $\boldsymbol{A}_{p 2, M-p 2-1}$ ならば

im $\boldsymbol{A}_{p 2+1+n, M-p 2-1-n}=\operatorname{im} \boldsymbol{A}_{p 2, M-p 2-1-n}$

が成り立つこととこの命題が成り立つことと同等であ る.そこで前者を帰納法により証明する. $n=0$ のとき仮 定により成り立つ. $n=k$ のとき成り立つ，すなわち

im $\boldsymbol{A}_{p 2+1+k, M-p 2-1-k}=\operatorname{im} \boldsymbol{A}_{p 2, M-p 2-1-k}$ が成り立つとする. そのとき任意の $u \in U$ に対し $F(M$ $\left.-\boldsymbol{p}_{2}-\mathbf{1}-\boldsymbol{k}, \boldsymbol{Y}\right)$ の意味で

$$
\begin{aligned}
& \underline{\alpha}\left(u^{p 2+1+k+t+1}\right)-\underline{\alpha}\left(u^{p 2+1+k+t}\right)=\sum \lambda\left(m, u_{i}\right) \\
& \underline{\alpha}\left(u_{i}^{m+t+1}\right)-\underline{\alpha}\left(u_{i}^{m+t}\right), 0 \leqq t \leqq M-p_{2}-1-k
\end{aligned}
$$

となる $\lambda\left(m, u_{i}\right) \in K, u_{i} \in U, 0 \leqq m \leqq p_{2}$ が存在する.し たがって $F\left(\boldsymbol{M}-\boldsymbol{p}_{2}-\mathbf{1}-\boldsymbol{k}-\mathbf{1}, \boldsymbol{Y}\right)$ の意味で

$\underline{S_{l}}\left\{\underline{\alpha}\left(u^{p 2+1+k+t}\right)-\underline{\alpha}\left(u^{p 2+k+t}\right)=\sum \lambda\left(m, u_{i}\right)\right.$

$\underline{S_{l}}\left\{\underline{\alpha}\left(u_{i}^{m+t}\right)-\underline{\alpha}\left(u_{i}^{m+t-1}\right)\right\}$

が成り立つ。ゆえに

$\operatorname{im} \boldsymbol{A}_{p 2+1+k+1, M-p 2-1-k-1}=\mathrm{im} \boldsymbol{A}_{p 2+1, M-p 2-1-k-1}$ が成り立つ.一方, $\operatorname{im} A_{p 2+1, M-p 2-1}=\operatorname{im} A_{p 2, M-p 2-1}$ が成 り立つことと任意の $j \leqq M-p_{2}-1$ に対し $\operatorname{im} A_{p 2+1 ; j}=$ $\operatorname{im} \boldsymbol{A}_{p 2, j}$ が成り立つことと同じである. したがって, im $A_{p 2+1+k+1, M-\dot{p} 2-1-k-1}=\operatorname{im} A_{p 2, M-p 2-1-k-1}$ が成り立つ. そ れゆえに $n=k+1$ のとき成り立つ.

（B.6）命題

部分補正一般インパルス応答関数 $G I\left(u_{i}\right) \in F(\boldsymbol{M}, \boldsymbol{Y})$, $1 \leqq i \leqq m$ に対応する部分線形入出力写像を $\boldsymbol{A}_{(}$，）とす る. そのとき $0 \leqq p_{2}<p_{1}<M$ を満たす整数 $p_{1}, p_{2}$ に対し $\operatorname{ker} \boldsymbol{A}_{p 1, M-p 1}=\operatorname{ker} \boldsymbol{A}_{p 1, M-p 1-1}$ ならぼ $\operatorname{ker} \boldsymbol{A}_{p 2, \boldsymbol{M}-p 1-1}=$ $\operatorname{ker} \boldsymbol{A}_{p 2, M-p 2}$ が成り立つ。

（証明）命題(B.6)は命題(B.5)の双対である。した がって, 命題(B.5) と同様に証明できる.

部分時不変入力応答関数 $\underline{\alpha}: U^{*}(\leqq M) \rightarrow \dot{Y}$, 同等的に 部分補正一般インパルス応答 $G I\left(u_{i}\right) \in F(M, Y), 1 \leqq i$ $\leqq m$ の部分実現系，自然部分実現系に関してつぎの補題 が定義により容易に得られる。

\section{(B.7) 補題}

部分補正一般インパルス応答 $G I\left(u_{i}\right) \in F(\boldsymbol{M}, \boldsymbol{Y}), 1 \leqq$ $i \leqq m$, 擬線形系 $\sigma=\left((\boldsymbol{X}, F), g, h, h^{0}\right)$ に対しつぎの事柄 が成立する。

1） $\sigma$ が $\underline{G I}$ の部分実現系であることと $0 \leq p<M$ な る任意の整数 $p$ に対し下図が可換であることと同等て ある。

2） $\sigma$ が $\underline{G I}$ の部分実現系であることと $0 \leqq p<M$ な る整数 $p$ に対し下図が可換であり， $\boldsymbol{G}_{p}$ が全射および $H_{M-p-1}$ が単射であることと同等である。 


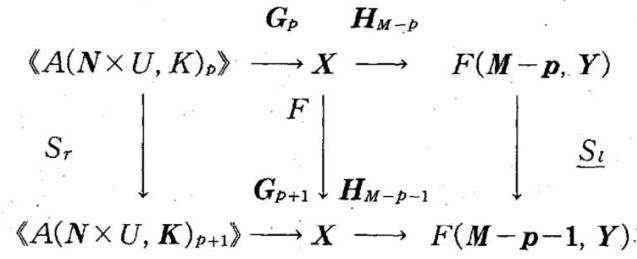

ただし $\boldsymbol{G}_{p}, \boldsymbol{H}_{q}$ は $g$ に対応する線形入力写像 $\boldsymbol{G}, h$ に対 応する線形観測写像 $H$ に対し $\boldsymbol{G}_{p}:=\boldsymbol{G} \cdot J_{p}, \boldsymbol{H}_{q}:=P_{q} \cdot \boldsymbol{H}$ である。

(B.8) 定理(3.7)の証明

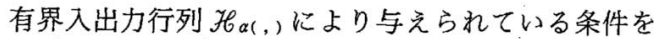
GI に対応する部分線形入出力写像 $A_{(}$, ，により同等的 に*) $: \operatorname{im} \boldsymbol{A}_{p, M-p-1}=\operatorname{im} \boldsymbol{A}_{p+1, M-p-1}$ および**) : ker $\boldsymbol{A}_{p, M-p}=\operatorname{Ker} \boldsymbol{A}_{p, M-p-1}$ とに書き換えられる.まず 最初 に上記の条件 1$) ， 2)$ が必要であることを示す， $\sigma=((\boldsymbol{X}$, $\left.F), g, h, h^{0}\right)$ を $\underline{G I}$ (同等的に $\underline{\alpha}$ ) の自然部分実現系とす る.そのとき $p+q<M$ を満たす $p, q \in N$ か゚存在して $\sigma$ は $p$-擬可到達であり $q$-可観測である.

$\boldsymbol{G}$ を $g$ に対応する線形入力写像, $\boldsymbol{H}$ を $h$ に対応する 線形観測写像とし,整数 $p^{\prime}, q^{\prime}$ を $p^{\prime} \geqq p, q^{\prime} \geqq q$ とする. そ こで $G_{p^{\prime}}:=G \cdot J_{p^{\prime}}$ は全射であり, $\boldsymbol{H}_{q}:=P_{q} \cdot \boldsymbol{H}$ は単射であ る.したがって部分線形入出力写像 $A_{p^{\prime}, q^{\prime}}:=H_{q^{\prime}} \cdot G_{p^{\prime}}$ は条 件*)，**)を満たす．うきに条件*)，**)が十分で あることを示す. $S:=\operatorname{ker} \boldsymbol{A}_{p+1, M-p-1}, Z:=\operatorname{im} \boldsymbol{A}_{p, M-p}$ と する.そのとき条件**)により写像 $\pi \cdot j: Z \rightarrow F(M$ $-\boldsymbol{p}, \boldsymbol{Y}) \rightarrow F(\boldsymbol{M}-\boldsymbol{p}-\mathbf{1}, \boldsymbol{Y})$ は単射である.ただし，jは 標準的単射であり， $\pi$ は標準的全射である。それゆえに $Z$ は命題(B.2)の条件 1)を満たす.*)により任意の $u$ $\in U に$ 対 $し A_{p+1, M-p-1}\left(e_{(p+1, u)}\right)=\boldsymbol{A}_{p, M-p-1}\left(\sum \lambda(1\right.$, $\left.\left.u_{i}\right) e_{(1, i)}\right)$ となる $e_{(i, u i)} \in\left\langle A(N \times U, \boldsymbol{K})_{p}\right\rangle$ が存在する. 補 題(B.4)の 1)により, $\boldsymbol{A}_{p+1, M-p-1}\left(e_{(p+1, u)}-i\left(\sum \lambda(1\right.\right.$, $\left.\left.\left.u_{i}\right) e_{(1, u i)}\right)\right)$ となり $e_{(p+1, u)}-i\left(\sum \lambda\left(1, u_{i}\right) e_{(1, u i)}\right) \in S$ で る. それゆえに $S$ は命題(B.1)の条件 2$)$ を満たす。 $\underline{j}$ を $\operatorname{im} \boldsymbol{A}_{p, \boldsymbol{M}-p-1} \rightarrow F(\boldsymbol{M}-\boldsymbol{p}-\mathbf{1}, \boldsymbol{Y})$ の標準的単射とすれば **)により $B:=(j)^{-1} \pi: j: Z \rightarrow \operatorname{im} \boldsymbol{A}_{p, M-p-1}$ は全単射な 線形写像である.'部分線形入出力写像 $\boldsymbol{A}_{p+1, M-p-1}$ : $\left\langle A(\boldsymbol{N} \times U, \boldsymbol{K})_{p+1}\right\rangle \rightarrow F(\boldsymbol{M}-\boldsymbol{p}-\mathbf{1}, \boldsymbol{Y})$ に伴う全単射な 線形写像 $\boldsymbol{A}^{b}:=\boldsymbol{A}_{p+1, M-p-1}^{b}:\left\langle A(\boldsymbol{N} \times U, \boldsymbol{K})_{p+1}\right\rangle / S \rightarrow \mathrm{im}$ $\boldsymbol{A}_{b+1, M-p-1}$ を考えれば*)により線形写像 $B^{-1} \cdot \boldsymbol{A}^{b}$ は $\left\langle A(N \times U, \boldsymbol{K})_{p+1}\right\rangle / S \rightarrow Z$ の全単射である.

任意の $\lambda \in 《 A(\boldsymbol{N} \times U, \boldsymbol{K})_{p} 》 \cap S$ に対し写像 $B^{-1} \cdot \boldsymbol{A}^{b}$ の単射性により $\boldsymbol{A}_{p, M-p}(\lambda)=0$ となる. そこで補題(B.7) の2）を用いれば $A_{p+1, M-p-1}\left(S_{r} \lambda\right)=\underline{S}_{\imath} A_{p, M-p}(\lambda)=0$ が成 り立ち $S_{r} \lambda \in S$ となる. したがって $S$ は命題(B.1)の1) を満たす。命題(B.1)により入力写像付き自由運動 $\left(\left(\left\langle A(N \times U, \boldsymbol{K})_{p+1}\right\rangle / S, \underline{S_{r}}\right), \bar{\eta}\right)$ は $p$-擬可到達である.
条件*)により任意の $z \in Z$ に対し $\underline{S_{l}} j(z)=\underline{j}(y)=$ $\underline{j} B\left(z^{\prime}\right)=\pi \cdot j\left(z^{\prime}\right)$ となり $\operatorname{im} \underline{S_{j}} \underline{i m}(\pi \cdot j)$ が成り立つ. それゆえに $Z$ は命題(B.2)の条件 2)を満たし, 命題 (B.2)により出力機構付き自由運動, $((Z, F) ; 0)$ は $q$-可 観測である(付録(B.2)の証明参照)。 $B^{-1} \cdot \boldsymbol{A}^{b}$ が (《A(N $\left.\left.\times U, \boldsymbol{K})_{p+1}\right\rangle / S, \underline{S_{r}}\right) \rightarrow(Z, F)$ の自由運動射であること がわかる.したがって互いに同形な擬線形系 $\sigma_{1}=$ $\left(\left(\left\langle A(\boldsymbol{N} \times U, \boldsymbol{K})_{p+1}\right\rangle / S, \underline{S_{r}}\right), \hat{\eta}, 0 \cdot B^{-1} \cdot \boldsymbol{A}^{b}, \underline{\alpha}(l)\right)$ と $\sigma_{2}$ $=\left((Z, F), B^{-1} \cdot A^{b} \cdot \hat{\eta}, 0, \underline{\alpha}(b)\right)$ とが得られ，それぞれ $\underline{\alpha}$ の自然部分実現系である。それゆえに $\alpha$ の自然部分実現 系が存在する。

(B.9) 補題

二つの正準擬線形系が同形であるための必要十分条件 はそれらの挙動が等しいことである.

（証明）補題(A.5)林よび文献 1)の定理 (3.5)により 明らかである。

(B.10) 定理(3.8)の証明

部分補正一般インパルス応答 $G I\left(u_{i}\right) \in F(M, Y), 1 \leqq$ $i \leqq m$ (同等的に部分時不変入力応答関数 $\alpha$ ) に対応する 部分線形入出力写像を $A_{(}$, とする. 最初に必要性を示 す. $G I$ の自然部分実現系が存在すると仮定する.そこで 異なる $p, p^{\prime}$ (ただし $\left.0 \leqq p^{\prime}<p<M\right)$ に対し定理 (3.8)が成 り立つ,すなわち, *) : im $\boldsymbol{A}_{p, M-p-1}=\operatorname{im} \boldsymbol{A}_{p+1, M-D-1}$ と* *) : $\operatorname{ker} \boldsymbol{A}_{p, M-p}=\operatorname{ker} \boldsymbol{A}_{p, M-p-1}$ お よび*)':im $\boldsymbol{A}_{p^{\prime},}$ ${ }_{M-p^{\prime}-1}=\operatorname{im} \boldsymbol{A}_{p^{\prime}+1, M-p^{\prime}-1}$ と **)': $\operatorname{ker} \boldsymbol{A}_{p^{\prime}, M-p^{\prime}}=\mathrm{ker}$ $A_{p^{\prime}, M-p^{\prime}-1}$ が成り立つ。 そのとき命題(B.5)，(B.6)によ り $Z=\operatorname{im} A_{p, M-p}$ と $Z^{\prime}:=\operatorname{im} A_{p^{\prime}, M-p^{\prime}}$ との次元は等し い. したがって, 状態空間を $Z, Z^{\prime}$ として定理 (3.6)の証 明の手順により得られる $\underline{\alpha}$ の自然部分実現系を $\sigma, \sigma$ と すれば，明らかに $\sigma$ と元とは同形である. 補題(B.9)に よればそれらの挙動は等しい.それゆえに $\underline{\alpha}$ の自然部分 奏現系は整数 $p, p^{\prime} に$ 拘らず同じである。したがって補題 (B.9)により $\underline{\alpha}$ の最小次元(正準)部分実現系は同形，す なわち一意である.つぎに十分性を対偶により示す， $\alpha$ の自然部分実現系が存在しないとする.そのとき $\alpha$ の最 小次元部分実現系は $p$-擬可到達, $q$-可観測, $p+q \geqq M$ て あり $p-1$ 未満では擬可到達であり， $q-1$ 末満では可観 測でない。そこで入力 $e_{(p, u)}$ により始めて到達する状態 $x$ の F による推移先を決定しょうとするとき観測デー タが高々 $(M-p-1)(<q)$ までの入力によるものしかな いので Fx を一意に決定することができない.したがっ て状態の推移を表わす $F$ を一意に決定することができ ない. ゆえに $\alpha$ の最小次元部分実現系は一意でない. 


\section{《付 録 C》}

ここでは，第 4，5 章の証明を行う。記枵は「証明終 わり」を表わす。

(C.1) 定理 (4.2)の証明

定理 (3.7)の証明(付録(B.8)参照)で得られた GI の 自然部分実現系 $\sigma_{2}=\left((Z, F), B^{-1} \cdot A^{b} \cdot \bar{\eta}, 0, \underline{\alpha}(l)\right)$ に対し 擬線形系射 $T_{s}: \sigma_{2}=\left((Z, F), B^{-1} \cdot A^{b} \cdot \tilde{\eta}, 0, \underline{\alpha}(l)\right) \rightarrow \sigma_{s}=$ $\left(\left(K^{n} \cdot F_{s}\right), g_{s}, h_{s}, h^{0}\right)$ を考えることにより得られる。

(C.2) 補題(5.3)の証明

列べクトル $\underline{S_{i}^{i} G I}\left(u_{1}\right) \in \boldsymbol{K}^{L-1}$ の第 $j$ 番目の成分が $\left(\underline{S_{i}^{i} G I}\left(u_{i}\right)\right)(j-1)=\alpha\left(u_{1}^{i+j}\right)-\alpha\left(u_{1}^{i+j-1}\right)$ であることに注 目すれば手順 1)により $\alpha\left(u_{1}^{k} \mid \omega_{1}\right), \forall k \in N$ が計算から一 意に決められる。 $\alpha$ が時不変であることから，任意の $k(1$ $\left.\leqq k \leqq L_{2}+L\right)$ に対し $\alpha\left(u_{1}^{k-1}\left|u_{2}\right| \omega_{1}\right)-\alpha\left(u_{1}^{k} \mid \omega_{1}\right)+\alpha\left(u_{1}^{k}\right)$ $-\alpha\left(u_{1}^{k-1}\right)=\alpha\left(u_{1}^{k-1} \mid u_{2}\right)-\alpha\left(u_{1}^{k-1}\right)=\left(\underline{S_{l}^{i} G I}\left(u_{2}\right)\right)(j-1), i$ $+j=k$ が得られる.よって入力 $\omega_{2}=u_{1}^{L 2+L-1} \mid u_{2}$ を付け加 えて手順 2) が調べられる。列べクトル $S_{l}^{i} G I\left(u_{2}\right)$ の第 $j$ 番目の成分が $\left(\underline{S_{l}^{i} G I}\left(u_{2}\right)\right)(j-1)=\alpha\left(u_{1}^{i+j}\left|u_{2}\right| \omega_{1}\right)$ $-\alpha\left(u_{1}^{i+j} \mid \omega_{1}\right)+\alpha\left(u_{1}^{i+j}\right)-\alpha\left(u_{1}^{i+j-1}\right)$ であるから手順 2) に より $\alpha\left(u u_{1}^{k}\left|\omega_{2}\right| \omega_{1}\right), 1 \leq k \in N$ が計算から一意に決められ る。 $\alpha$ が時不変であることから，任意の $k\left(1 \leqq k \leqq L_{3}+L\right)$ に対し $\alpha\left(u_{1}^{k-1}\left|u_{3}\right| \omega_{2} \mid \omega_{1}\right)-\alpha\left(\cdot u_{1}^{k}\left|\omega_{2}\right| \omega_{1}\right)+\alpha\left(u_{1}^{k}\right)-\alpha\left(u_{1}^{k-1}\right)$ $=\alpha\left(u_{1}^{k-1} \mid u_{3}\right)-\alpha\left(u_{1}^{k-1}\right)=\left(\underline{S_{i}^{i} G I}\left(u_{3}\right)\right)(j-1), i+j=k$ が 得られる.さらに入力 $\omega_{3}:=u_{1}^{L 3+L-1} \mid u_{3}$ を付け加えて手順 3)が調べられる. 列べクトル $\underline{S_{i}^{i} G I}\left(u_{3}\right)$ の第 $j$ 番目の成
分怔 $\left(\underline{S_{l}^{i} G I}\left(u_{3}\right)\right)(j-1)=\alpha\left(u_{1}^{k-1} \mid u_{3}\right)-a\left(u_{1}^{h-1}\right)=$ $\alpha\left(u_{1}^{k-1}\left|u_{3}\right| \omega_{2} \mid \omega_{1}\right)-\alpha\left(u_{1}^{k}\left|\omega_{2}\right| \omega_{1}\right)+\alpha\left(u_{1}^{k}\right)-\alpha\left(u_{1}^{k-1}\right), i+j=$ $k$ であるから手順 3) により $\alpha\left(u_{1}^{k}\left|\omega_{3}\right| \omega_{2} \mid \omega_{1}\right), \forall k \in N$ が計 算加ら一意に決められる。

…以下同様の㐿順を施して有界入出力行列 $\mathscr{H}_{\alpha(p, L-1)}$ が得られる。

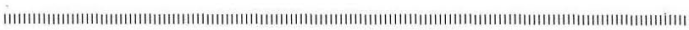

$$
\text { [著 者 紹 介] }
$$

\section{長谷川 泰 道 (正会員)}

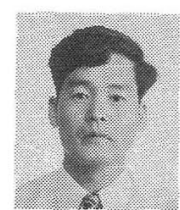

1976 年, 名古屋大学大学院工学研究科博 士課程修了. 現在, 岐皁大学丁学部電子情 報工学科助教授。特に離散時間非線形系の システム理論および 2 次元図形の研究に従 事(工学博士).

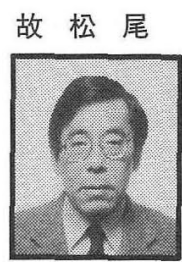

強

1961 年, 名古屋大学工学部電気学科卒 業。同富士電機製造 (株) 入社. 63 年名古屋 大学助手. $72 \sim 75$ 年フロリダ大学数学的シ ステム理論センター研究員. 84 ～ 89 年名古 屋大学工学部講師扔よび助教授. 89 年東邦 大学理学部教授。93 年 4 月死去。制御理論, システム理諭の研究に従事した(工学博 士〉。

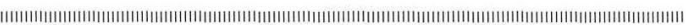

